Research Article

\title{
Occupational Exposure to Blood and Body Fluids among Health Care Workers in Gondar Town, Northwest Ethiopia: A Result from Cross-Sectional Study
}

\author{
Giziew Abere (D), Dawit Getachew Yenealem (D), and Sintayehu Daba Wami \\ Department of Environmental and Occupational Health and Safety, Institute of Public Health, University of Gondar, \\ P.O. Box 196, Gondar, Ethiopia \\ Correspondence should be addressed to Giziew Abere; gabere2010@yahoo.com
}

Received 2 September 2019; Revised 21 April 2020; Accepted 5 May 2020; Published 15 May 2020

Academic Editor: Pam R. Factor-Litvak

Copyright (C) 2020 Giziew Abere et al. This is an open access article distributed under the Creative Commons Attribution License, which permits unrestricted use, distribution, and reproduction in any medium, provided the original work is properly cited.

Background. Health care workers are at the greatest risk of developing blood-borne diseases through occupational exposure to blood and other contaminated body fluids. Occupational exposure to blood and body fluids (BBFs) continues to be the major public health problems and serious concern for the health care force in Ethiopia. Therefore, this study was aimed to determine the prevalence of exposure to blood and other body fluids and its associated risk factors among health care workers. Methods. The institution-based cross-sectional study design was employed from January 20 to February 30, 2018. A stratified random sampling followed by a simple random sampling technique was used to select 286 study participants. Data were collected using a pretested and structured questionnaire. Bivariate and multivariable logistic regression analyses were performed to identify factors associated with occupational exposure to BBFs. The significance level was obtained at a 95\% confidence interval (CI) and $p$ value $\leq 0.05$. Results. The prevalence of occupational exposure to blood and body fluids among health care workers in the last 12 months was 65.3\% (95\% CI: 59.4, 70.9). Lack of readily available personal protective equipment (adjusted odds ratio (AOR)) $=3.01,95 \%$ CI: $1.56,5.84)$, lack of training $(\mathrm{AOR}=3.36,95 \% \mathrm{CI}: 1.1,11.2)$, Khat chewing $(\mathrm{AOR}=2.74,95 \% \mathrm{CI}: 1.3,5.8)$, and being a medical doctor $(\mathrm{AOR}=5.1,95 \% \mathrm{CI}: 1.68,15.21)$ were significantly associated risk factors with occupational exposure to blood and other body fluids. Conclusions. In this study, occupational exposure to blood and other body fluids among health care workers remains a major health problem. Hence, ensuring the availability of personal protective equipment, developing strategies on banning, and strict monitoring of Khat chewing and training on infection prevention should be emphasized to minimize the problem.

\section{Introduction}

Worldwide occupational exposure to blood and body fluids is a major health care-related problem [1] that becomes ubiquitous means of exposure to blood-borne pathogens [2]. According to different studies from 35 million health care workers (HCWs), $2[3]$ up to $3[1,4]$ millions are exposed to blood-borne diseases. As a consequence of occupational exposures, 66,000 HBV, 16,000 HCV, and 1,000 HIV infections occur among HCWs each year $[5,6]$.

Occupational exposure to blood and body fluids is accidental contact with blood and body fluids during a medical intervention by HCWs [7]. It can result from percutaneous and mucocutaneous injury or blood contact with nonintact skin [8]. The most common means of exposure to blood and body fluids in health care sectors happen to be needle stick and sharp injuries [9-12] and a considerable number of researches equate both [13]. In light of this evidence, worldwide estimates indicate that 1 in 10 health care workers experience a sharp injury every year $[14,15]$.

The risk of accidental exposure to blood and body fluids is linked to activities like taking blood samples [16, 17], giving injections [16, 18], recapping of already used needles $[13,16,18-20]$, surgery $[16,21]$, delivery, giving emergency care, cleaning up transportation of waste products $[16,19]$, and instrument processing procedures $[13,16,18,19]$. While engaging in such routine clinical activities in health facilities, HCWs are at risk of occupationally acquired infections via blood and body fluid exposure $[9,22,23]$. 
Although CDC devised standard precautions as the best intervention to prevent blood and body fluid exposures [24], it has been shredded with inadequate and nonuniform adherence across practitioners [25] which can be attributed to underestimation of the hazard [10]. Because many people with blood-borne infections do not have symptoms, it is necessary to apply standard precaution measures to all clients and patients [26]. Unfortunately, despite the simplicity and clarity of these precautions, the practice among HCW s in the clinical settings is low, especially in resourcelimited settings [27], thus exposing HCWs to the risk of infection $[25,28]$. Furthermore, the World Health Organization (WHO) has recommended governments to transition to the exclusive use of safety injection devices by 2020 [29].

Regardless of the efforts taken, findings indicate that health care workers are at high risk of contracting bloodborne illnesses such as HCV, HBV, and HIV [15] that is associated with significant mortality and morbidity of health care workers [30].

According to the study in 21 African countries, the estimated pooled 12-month prevalence of occupational exposure to body fluids was found to be $48.0 \%$ [2]. In another study, the prevalence of occupational exposure to $\mathrm{BBF}$ is $79 \%$ [31]. The magnitude of blood and body fluid exposures in Ethiopia ranges from $29.2 \%$ to $65.9 \%$ [4, 22, 32].

The occupational risk of exposure to BBFs and needle stick injuries not only affects the safety and wellbeing of HCWs [33] but also compromises the quality of health care delivered [1, 4], and a decrease of the attrition rate also indicated consequences that eventually lead to a shortage and crisis [34, 35]. Reports showed that occupational risks are also the main triggering issues in strikes and other complaints by health force in low-income countries [36]. Moreover, occupational blood exposure results in substantial psychological problems, such as job-related depression and anxiety [37] and considerable management costs ranging from 650 to 750 US dollars [38]. Even the fear of occupational transmission of BBV may cause HCW to change occupations [39].

Based on the evidence generated from different research outputs, there is an association between work experience $[4,19,32]$, type of profession $[32,40]$, workplace factors like lack of training on IP $[17,32,40]$, and occupational exposure to blood and other body fluids. In addition, inconsistent use of PPE particularly gloves and not complying with standard precautions [4, 32], sex [17, 19], being single [17], and older age are implicated as associated factors [19].

Even though efforts have been taken, occupational exposure to blood and body fluids continues to be the major public health problem and is a serious concern for the health care force in Ethiopia. Occupational exposure to blood and body fluids demands updated information regarding its magnitude and associated factors since there is dynamism in health care force composition and behaviors. Such a study will have a significant input in the formulation and revision of the appropriate strategy to modify and facilitate the overall prevention of occupational exposure to BBFs. Therefore, this study aimed to determine the current prevalence and associated factors in Gondar town health care facilities.

\section{Materials and Methods}

2.1. Study Design and Setting. The institutional-based crosssectional study design was employed. The study was conducted in Gondar town from January 20 to February 30, 2018. Gondar town is located north of Addis Ababa at $737 \mathrm{~km}$ and was founded in 1635. Based on the 2017 national census conducted by the Central Statistical Agency of Ethiopia (CSA), Gondar had a total population of 360,600 . In Gondar, there are eight health centers and one referral hospital, which had a total of more than 1004 health care workers.

2.2. Study Population. Health care workers who were working at hospitals and health centers in Gondar town with one-year experience were included in the study. However, health care workers who were in annual leave and who were critically ill during the data collection period were excluded from the study.

2.3. Sample Size and Sampling Technique. The sample size was determined using single population proportion formula assuming a population proportion of $65 \%$ [4], a margin of error $5 \%$, and confidence interval of $95 \%$; since the total population was less than 10,000 , we have used reduction formula resulting in 286 health care workers.

A stratified random sampling technique followed by simple random sampling was used to select 286 study participants using a proportional allocation from the nine health institutions by considering each health center and hospital as a stratum.

2.4. Operational Definition. Health care workers, for this study, are defined as workers essential to provide health care delivery and have direct and indirect contact with patients. Those include health officers, nurses, midwives, medical doctors, pharmacists, and medical laboratory professionals.

Occupational exposure to blood and body fluid refers to reasonably anticipated skin, eye, mucous membrane, or parenteral contact with blood, body fluids, or other potentially infectious material that may result from the performance of one's professional duties [41].

Body fluids are liquids originating from inside the bodies of living people. They include fluids that are excreted or secreted from the body.

The availability of PPE is the accessibility of specialized clothing or equipment worn by professionals for protection against health and safety hazards in the health facilities.

Khat chewer is a health care professional chewing Khat (a mildly psychoactive substance) used three times a week for at least 1 year [42].

2.5. Data Collection Tools and Procedures. Data was collected using a pretested and structured questionnaire through a selfadministered technique. The questionnaire was developed 
from different studies in the literature to assess the health care worker's exposure to BBFs and had three parts. The first part covered sociodemographic characteristics, the second part covered the behavioral and working environment variables, and the third part covered the occupational exposure of HCWs to blood and other body fluids.

2.6. Data Quality Control. The training was given for data collectors and supervisors for two days on procedures, techniques, and ways of data collection. Before the commencement of the actual data collection process, the questionnaire was pretested at Debre Tabor District Hospital. Besides, continuous and strict supervision was carried out during the data collection process.

2.7. Data Processing and Analysis. Data was entered using Epi-Info version 7.1 and cleaned and analyzed using SPSS (Statistical Package for Social Sciences), version 20.0. Descriptive statistics such as frequency, mean, percentage, and standard deviations were calculated to describe the characteristics of the study population in relation to different variables. The binary logistic regression model was fitted to identify factors associated with BBFs. Blood and other body fluids were regressed against the sociodemographic, behavioral, and work environment factors separately. Before fitting the binary logistic regression model, the goodness of model fit test was checked by Hosmer and Lemeshow test, and the assumption was satisfied ( $p$ value $>0.05$ ). The significance level was obtained at $95 \% \mathrm{CI}$ and $p$ value $\leq 0.05$. The adjusted odds ratio was used to determine the strength of association.

\section{Results}

3.1. Sociodemographic Characteristics of Respondents. A total of 277 HCWs participated in the study, which gives a response rate of $96.8 \%$. The majority, 165 (59.6\%), of health professionals in this study were males, and the age of 198 (71.4\%) of the respondents was in the range of 25-32 years. Regarding their educational level, the majority, $184(66.4 \%)$, of the study participants had a B.S. degree, and $84(30.3 \%)$ were nurses. Below a quarter, $60(21.7 \%)$ were working in outpatient departments, and $104(37.5 \%)$ had 3-5 years of work experience (Table 1).

3.2. Behavioral Characteristics of Respondents. The majority, 264 (95.3\%), of the study participants had used at least one personal protective equipment (PPE) during the last health care procedure. Above half, 171 (61.7\%), of health care workers washed their hands before and after any health care procedure or handling of BBF-contaminated waste, and only $135(48.7 \%)$ of the study participants complied with the standard precautions.

Of the total study participants (277), 74 (26.7\%) of the respondents were Khat chewers and 206 (74.3\%) of the respondents drank alcohol; among them, a high proportion, 133 (64.5\%), drank occasionally. Ninety-six (34.7\%) of health care workers reported that they had a sleeping problem (Table 2).
TABLE 1: Distribution of sociodemographic characteristics of study participants in Gondar town, northwest Ethiopia, $2018(n=277)$.

\begin{tabular}{|c|c|c|}
\hline Variable & Frequency & Percent (\%) \\
\hline \multicolumn{3}{|l|}{ Sex } \\
\hline Male & 165 & 59.6 \\
\hline Female & 112 & 40.4 \\
\hline \multicolumn{3}{|l|}{ Age } \\
\hline$\leq 24$ & 33 & 11.9 \\
\hline $25-27$ & 107 & 38.6 \\
\hline $28-32$ & 91 & 32.9 \\
\hline$\geq 33$ & 46 & 16.6 \\
\hline \multicolumn{3}{|l|}{ Level of education } \\
\hline Diploma & 51 & 18.4 \\
\hline Degree & 184 & 66.4 \\
\hline Masters and above & 42 & 15.2 \\
\hline \multicolumn{3}{|l|}{ Marital status } \\
\hline Single & 165 & 59.6 \\
\hline Married & 112 & 40.4 \\
\hline \multicolumn{3}{|l|}{ Profession } \\
\hline Nurse & 84 & 30.3 \\
\hline Medical doctor & 48 & 17.3 \\
\hline Laboratory technology & 40 & 14.4 \\
\hline Health officer & 24 & 8.7 \\
\hline Midwife & 65 & 23.5 \\
\hline Pharmacy & 16 & 5.8 \\
\hline \multicolumn{3}{|l|}{ Department } \\
\hline Outpatient & 60 & 21.7 \\
\hline Injection and dressing & 27 & 9.7 \\
\hline Surgical & 18 & 6.5 \\
\hline Pediatrics & 42 & 15.2 \\
\hline Gynecology & 42 & 15.2 \\
\hline Medical & 11 & 4.0 \\
\hline Laboratory & 39 & 14.1 \\
\hline Others & 38 & 13.7 \\
\hline \multicolumn{3}{|l|}{ Work experience } \\
\hline$\leq 2$ years & 98 & 35.4 \\
\hline $3-5$ years & 104 & 37.5 \\
\hline$\geq 6$ years & 75 & 27.1 \\
\hline
\end{tabular}

3.3. Work Environment Factors. The majority, 253 (91.3\%), of the respondents had taken training on infection prevention. More than half of the study participants (53.1\%) reported that there was readily available personal protection equipment (PPE) available over the past year. Nearly half, 133 (48\%), of the study participants reported the presence of safety signs in their working unit. Only 95 (34.3\%) of the study participants reported that there were enough hand washing basins in their department of work. Though 155 (56\%) of the study participants reported that there was no infection prevention committee in the health care facility, the same number of study participants reported that there was workplace safety service for the prevention of occupational exposure to BBFs (Table 3).

3.4. Prevalence of Occupational Exposure to Blood and Body Fluids. Of the total, 241 (87\%) study participants had been exposed to blood and other body fluids in their lifetime. Moreover, the lifetime prevalence of the sharp injury of 
TABLE 2: Distribution of behavioral characteristics of respondents in health institutions in Gondar City, Northwest Ethiopia, 2018 ( $n=277)$.

\begin{tabular}{|c|c|c|}
\hline Variable & Frequency & Percent (\%) \\
\hline \multicolumn{3}{|l|}{ Use of PPE } \\
\hline Yes & 264 & 95.3 \\
\hline No & 13 & 4.7 \\
\hline \multicolumn{3}{|c|}{ Practice of washing hands before and after any health care procedure or handling of waste } \\
\hline Yes & 171 & 61.7 \\
\hline No & 106 & 38.3 \\
\hline \multicolumn{3}{|c|}{ Compliance with standard precautions } \\
\hline Yes & 135 & 48.7 \\
\hline No & 142 & 51.3 \\
\hline \multicolumn{3}{|l|}{ Khat chewing } \\
\hline Yes & 74 & 26.7 \\
\hline No & 203 & 73.3 \\
\hline \multicolumn{3}{|l|}{ Drinking alcohol } \\
\hline Everyday & 40 & 14.4 \\
\hline Once a week & 33 & 11.9 \\
\hline Occasionally & 133 & 48.0 \\
\hline Never & 71 & 25.6 \\
\hline \multicolumn{3}{|l|}{ Sleeping problem } \\
\hline Yes & 96 & 34.7 \\
\hline No & 181 & 65.3 \\
\hline
\end{tabular}

TABLE 3: Institutional factors on occupational exposure to blood and body fluids among health care workers in Gondar town, northwest Ethiopia, $2018(n=277)$.

\begin{tabular}{|c|c|c|}
\hline Variable & Frequency & Percent (\%) \\
\hline \multicolumn{3}{|c|}{ Training on prevention of infection } \\
\hline Yes & 253 & 91.3 \\
\hline No & 24 & 8.7 \\
\hline \multicolumn{3}{|c|}{ Readily availability of personal protective equipment throughout the year } \\
\hline Yes & 147 & 53.1 \\
\hline No & 130 & 46.9 \\
\hline \multicolumn{3}{|c|}{ Presence of safety signs in their working unit } \\
\hline Yes & 133 & 48 \\
\hline No & 144 & 52 \\
\hline \multicolumn{3}{|c|}{ Presence of enough hand washing facilities in the department or ward } \\
\hline Yes & 95 & 34.3 \\
\hline No & 182 & 65.7 \\
\hline \multicolumn{3}{|c|}{ Presence of infection prevention committee in the health care institution } \\
\hline Yes & 122 & 44.00 \\
\hline No & 155 & 56.00 \\
\hline \multicolumn{3}{|c|}{ Presence of workplace safety service } \\
\hline Yes & 155 & 56.00 \\
\hline No & 122 & 44.00 \\
\hline
\end{tabular}

health care workers was $73.3 \%$ (95\% CI: 67.7, 78.4). However, $181(65.3 \%)(95 \%$ CI: 59.4, 70.9) of health care workers were exposed to BBFs in the past year. Among those exposed, almost half, 90 (49.7\%), of them were exposed two or three times per year (Table 4).

3.5. Factors Associated with Occupational Exposure to Blood and Body Fluids. The multivariable logistic regression analysis showed that the lack of readily available/shortage of personal protective equipment, lack of training on infection prevention, Khat chewing, and profession/being a medical doctor were found to be significantly associated risk factors with occupational exposure to blood and other body fluids at $p$ value $<0.05$ (Table 5).

In this study, HCWs who perceived a lack of readily availability PPE in the health facility had a higher risk of BBF exposure. Health care workers who reported that there is lack of readily available/shortage of PPE had 3.01 times higher odds of exposure to blood and body fluids when compared to those who had perceived that there was readily accessible personal protective equipment $(\mathrm{AOR}=3.01,95 \%$ CI: $1.56,5.84)$.

Lack of training on infection prevention was associated with a high likelihood of experiencing BBF exposure. Health care workers who did not take training on infection 
TABLE 4: Occupational exposure to blood and body fluids among health care professionals in Gondar town, northwest Ethiopia, 2018 $(n=277)$.

\begin{tabular}{|c|c|c|}
\hline Variable & Frequency & Percent (\%) \\
\hline \multicolumn{3}{|c|}{ Lifetime occupational exposure to blood and body fluids } \\
\hline Yes & 241 & 87 \\
\hline No & 36 & 13 \\
\hline \multicolumn{3}{|c|}{ Lifetime sharp injury exposure } \\
\hline Yes & 203 & 73.3 \\
\hline No & 74 & 26.7 \\
\hline \multicolumn{3}{|c|}{ Occupational exposure to blood and body fluids in the past year } \\
\hline Yes & 181 & 65.3 \\
\hline No & 96 & 34.7 \\
\hline \multicolumn{3}{|c|}{ Frequency of BBF in the past one year } \\
\hline No & 96 & 34.7 \\
\hline Once & 62 & 22.4 \\
\hline Two or three & 90 & 32.5 \\
\hline Four and above & 29 & 10.4 \\
\hline
\end{tabular}

prevention had 3.36 times higher odds of being exposed to $\mathrm{BBF}$ compared to those who had taken training $(\mathrm{AOR}=3.36$, 95\% CI: 1.1, 11.2). Health care workers who chew Khat had 2.74 times higher chance of being exposed to blood and body fluids compared to non-Khat chewers $(\mathrm{AOR}=2.74,95 \% \mathrm{CI}$ : $1.3,5.8)$. In addition, study participants who are medical doctors in the profession had 5.1 times higher odds of exposure to $\mathrm{BBF}$ when compared to nurses $(\mathrm{AOR}=5.1,95 \%$ CI: $1.68,15.21)$.

\section{Discussion}

In this study, the period prevalence of BBF among HCWs was high. Being a medical doctor, lack of training, Khat chewing, and readily unavailability of PPE were the significant predictors for the BBF exposure.

According to this study, the prevalence of exposure to blood and other body fluids among health care workers during the last 12 months was $65.3 \%$ (95\% CI: 59.4, 70.9). This result showed that a high proportion of health care providers are exposed to blood and other body fluids which indicated that they are threatened by the transmission of blood-borne pathogens including Hepatitis B Virus (HBV), Hepatitis C Virus (HCV), and HIV/AIDS virus. The finding is in agreement with the prevalence rate reported in Bahir Dar (65.9\%), Mizan Tepi (64.1\%), and Kaduna state in Nigeria (68\%) $[1,4,19]$. However, the prevalence rate in our study was higher than the study done in Addis Ababa (41.3\%), Johannesburg metropolitan district (25.2\%), Tanzania (48.6), Lebanon (30\%), Fako division (50.9\%), Tehran (53.4), and Kenya (25\%) $[32,41,43-47]$. This difference may be attributed to the difference in regular training about safety precautions and infection prevention, inadequate supervision by health administrators, and infrastructure development [7]. In addition, poor workplace safety and a high load of patients in the facilities in our study setting could not be ruled out.

In this study, physicians were at high risk of exposure to blood and body fluids. Though some studies have shown that nurses have higher blood and body fluid exposure rates than physicians $[48,49]$, there have been some studies reporting higher rates among physicians [1, 50-52]. The latter is further supported by this study. This might be explained due to the fact that physicians are few in numbers and they work in different clinical procedures and relatively spent long working hours. This, in turn, makes them exhausted and put them at high risk of exposure to blood and body fluids.

Lack of readily available/shortage of personal protective equipment was significantly associated with occupational exposure to blood and body fluids. This is supported by the study done in Ethiopia [32, 53] and China [54] in which a shortage of available personal protective equipment was indicated as a factor associated with occupational exposure to blood and other body fluids. This finding might explain that the ready availability of personal protective equipment enabled health care workers to use personal protective equipment that has the potential to prevent the exposure of contaminated blood and body fluids. This, in turn, gives a hand to comply with standard precautions. Besides, frequent inaccessibility of personal protective equipment could decrease the motivation of previously energetic health care providers and could be a reason to be exposed to contaminated blood and body fluids. Furthermore, the unavailability of PPE might have a psychological effect on HWs. It can distract their concentration; they become dissatisfied and finally might lead them to stress, which will, in turn, be a risk for BBF exposure.

Moreover, the lack of training on infection prevention was a risk factor for occupational exposure to blood and body fluids. Health care professionals who did not take training on occupational infection prevention had higher odds of occupational exposure to BBF than those who had taken the training. This result is in agreement with the study findings from regional hospitals in Ethiopia [55], Addis Ababa [32], Jimma [17], and Tanzania [56]. This might be because training on infection prevention increases the chance of getting updated information and skills about procedures and mechanisms which might reduce the likelihood of occupational exposure to blood and body fluids [57]. Moreover, as the training enabled health care workers to know the consequence of blood and body fluid exposure, their adherence to standard precaution tends to be increased; thereby, the chance to be exposed to blood and body fluids would be decreased. 
TABLE 5: Bivariate and multivariable analysis of factors associated with occupational exposure to blood and body fluids among health care workers in Gondar town, northwest Ethiopia, $2018(N=286)$.

\begin{tabular}{|c|c|c|c|c|}
\hline \multirow[t]{2}{*}{ Variable } & \multicolumn{2}{|c|}{$\begin{array}{l}\text { Occupational } \\
\text { exposure to blood } \\
\text { and body fluids }\end{array}$} & \multirow[t]{2}{*}{ COR $(95 \%, C I)$} & \multirow[t]{2}{*}{$\operatorname{AOR}(95 \%, C I)$} \\
\hline & Yes & No & & \\
\hline \multicolumn{5}{|l|}{ Sex } \\
\hline Male & 107 & 58 & 1.00 & 1.00 \\
\hline Female & 74 & 38 & $1.06(0.63,1.74)$ & $1.08(0.58,2.04)$ \\
\hline \multicolumn{5}{|l|}{ Age } \\
\hline$\leq 24$ & 18 & 15 & 1.00 & 1.00 \\
\hline $25-27$ & 68 & 39 & $1.45(0.65,3.20)$ & $1.26(0.49,3.21)$ \\
\hline $28-32$ & 62 & 29 & $1.78(0.78,4.02)$ & $1.15(0.34,3.86)$ \\
\hline$\geq 33$ & 33 & 13 & $2.11(0.82,5.40)$ & $1.14(0.23,5.58)$ \\
\hline \multicolumn{5}{|l|}{ Work experience } \\
\hline$\leq 2$ & 60 & 38 & 1.00 & 1.00 \\
\hline $3-5$ & 67 & 37 & $1.14(0.64,2.03)$ & $1.42(0.61,3.23)$ \\
\hline$\geq 6$ & 54 & 21 & $1.62(0.85,3.11)$ & $2.49(0.63,9.89)$ \\
\hline \multicolumn{5}{|l|}{ Profession } \\
\hline Nurse & 50 & 34 & 1.00 & 1.00 \\
\hline Medical doctors & 39 & 9 & $2.94(1.26,6.86)^{* *}$ & $5.1(1.68,15.21)^{* *}$ \\
\hline Laboratory technologist & 26 & 14 & $1.26(0.57,2.76)$ & $0.41(0.03,5.59)$ \\
\hline Health officers & 14 & 10 & $0.95(0.37,2.39)$ & $1.55(0.47,5.11)$ \\
\hline Midwifery & 41 & 24 & $1.16(0.59,2.26)$ & $2.58(0.85,7.82)$ \\
\hline pharmacy & 11 & 5 & $1.49(0.47,4.69)$ & $1.61(0.32,8.20)$ \\
\hline \multicolumn{5}{|l|}{ Working departments } \\
\hline Outpatient department & 38 & 22 & 1.00 & 1.00 \\
\hline Injection and dressing & 20 & 7 & $1.65(0.60,4.54)$ & $2.60(0.81,8.35)$ \\
\hline Surgical departments & 14 & 4 & $2.02(0.59,6.92)$ & $0.87(0.19,3.83)$ \\
\hline Pediatrics & 27 & 15 & $1.04(0.46,2.36)$ & $0.93(0.29,2.91)$ \\
\hline Gynecology & 25 & 17 & $0.85(0.37,1.91)$ & $0.46(0.13,1.61)$ \\
\hline Medical departments & 7 & 4 & $1.01(0.26,3.85)$ & $0.65(0.12,3.53)$ \\
\hline Laboratories & 26 & 13 & $1.15(0.49,2.70)$ & $4.57(0.32,35.00)$ \\
\hline Others & 24 & 14 & $0.99(0.43,2.30)$ & $1.20(0.36,4.00)$ \\
\hline \multicolumn{5}{|l|}{ Readily availability of PPE } \\
\hline Yes & 82 & 65 & 1.00 & 1.00 \\
\hline No & 99 & 31 & $2.53(1.50,4.25)^{* *}$ & $3.01(1.56,5.84)^{* *}$ \\
\hline \multicolumn{5}{|c|}{ Training on infection prevention } \\
\hline Yes & 162 & 91 & 1.00 & 1.00 \\
\hline No & 19 & 5 & $2.13(0.77,5.90)$ & $3.36(1.1,11.2)^{*}$ \\
\hline \multicolumn{5}{|l|}{ Khat chewing } \\
\hline Yes & 58 & 19 & $2.35(1.26,4.38)^{* *}$ & $2.74(1.3,5.8)^{*}$ \\
\hline No & 123 & 80 & 1.00 & 1.00 \\
\hline
\end{tabular}

Note. 1 : 00: reference, PPE: personal protection equipment, ${ }^{*} p$ value $<0.05,{ }^{* *} p$ value $\leq 0.005$

Furthermore, health care workers who chew Khat had reported a higher chance of exposure to blood and other body fluids compared to non-Khat chewers. This might be due to its inherent effect on their behavior and it impaired workers' concentration and performance, anxiety, and trouble sleeping. A high blood level of such substances during work will endanger both safety and efficiency and will be the cause of increased likelihood of mistakes, not adhering to standard operating procedures, poor decision making, and errors in judgment. This is supported by the study done in Ethiopia in which Khat chewing was identified as significantly associated with workplace injury $[42,58]$. Moreover, the study done in the UK identified that Khat chewing has been found to decrease work capability and increase the rate of accidents [59].
4.1. Limitations of the Study. This study has shared the limitations of cross-sectional studies, the difficulty of determining causal relationships between BBFs and predictor variables. In addition, the possibility of recall bias could not be ruled out since worse and recent BBF exposure was better than the less serious and older ones.

\section{Conclusion}

A higher proportion of health care providers were found to be exposed to BBFs in this study. Lack of readily available/ shortage of personal protective equipment, Khat chewing, and lack of training on infection prevention were found to be predictors of occupational exposure to BBFs among health 
care workers. Therefore, ensuring ready availability of personal protective equipment, developing strategies on banning, strict monitoring and education on Khat chewing, and training on infection prevention should be emphasized to minimize occupational exposures to BBFs.

$\begin{array}{ll}\text { Abbreviations } \\ \text { AOR: } & \text { Adjusted odds ratio } \\ \text { BBFs: } & \text { Blood and body fluids } \\ \text { CI: } & \text { Confidence interval } \\ \text { COR: } & \text { Crude odds ratio } \\ \text { HCWs: } & \text { Health care workers } \\ \text { PPE: } & \text { Personal protective equipment } \\ \text { SPSS: } & \text { Statistical Package for Social Science } \\ \text { UK: } & \text { United Kingdom. }\end{array}$

\section{Data Availability}

All data generated or analyzed during this study are included in this article. The data that support the findings of this study are also available from the corresponding author upon reasonable request.

\section{Ethical Approval}

Ethical clearance was obtained from the Ethical Review Committee of Institute of Public Health, College of Medicine and Health Sciences, University of Gondar.

\section{Consent}

A permission letter was also obtained from each health institution administrator. Those health care providers, who were selected to participate, were informed about the purpose of the study and the importance of their participation and that they can withdraw at any time. Written consent was obtained prior to data collection.

\section{Conflicts of Interest}

The authors declare that there are no conflicts of interest.

\section{Authors' Contributions}

GA wrote the proposal, participated in data collection, analyzed the data, and drafted the manuscript. DGY and SDW reviewed the proposal, participated in data analysis and wrote the manuscript. All authors read and approved the final manuscript.

\section{Acknowledgments}

The authors are very grateful to supervisors, data collectors, and all study participants for their contributions to the success of this study.

\section{References}

[1] T. Mekonnin, A. Tsegaye, A. Berihun, H. Kassachew, and A. Sileshi, "Occupational exposure to blood and body fluids among health care workers in mizan Tepi university teaching hospital, bench maji zone, south west Ethiopia," Medical Safety \& Global Health, vol. 7, no. 2, pp. 2574-0407, Article ID 1000146, 2018.

[2] A. Auta, E. O. Adewuyi, A. Tor-Anyiin et al., "Health-care workers' occupational exposures to body fluids in 21 countries in Africa: systematic review and meta-analysis," Bulletin of the World Health Organization, vol. 95, no. 12, pp. 831-841F, 2017.

[3] T. J. C. Mission, Improving Patient and Worker Safety Opportunities for Synergy, Collaboration and Innovation, The Joint Commission, Oakbrook Terrace, IL, USA, 2012.

[4] M. A. Yenesew and G. A. Fekadu, "Occupational exposure to blood and body fluids among health care professionals in Bahir Dar town, Northwest Ethiopia," Safety and Health at Work, vol. 5, no. 1, pp. 17-22, 2014.

[5] A. Prüss-Üstün, E. Rapiti, and Y. Hutin, "Estimation of the global burden of disease attributable to contaminated sharps injuries among health-care workers," American Journal of Industrial Medicine, vol. 48, no. 6, pp. 482-490, 2005.

[6] G. Kassa, D. Selenic, M. Lahuerta et al., "Occupational exposure to bloodborne pathogens among health care workers in Botswana: reporting and utilization of postexposure prophylaxis," American Journal of Infection Control, vol. 44, no. 8, pp. 879-885, 2016.

[7] J. Yasin, R. Fisseha, F. Mekonnen, and K. Yirdaw, "Occupational exposure to blood and body fluids and associated factors among health care workers at the University of Gondar Hospital, Northwest Ethiopia," Environmental Health and Preventive Medicine, vol. 24, no. 1, p. 18, 2019.

[8] National Institute for Occupational Safety and Health, A, Worker Health Chart Book, 2004, National Institute for Occupational Safety and Health, Cincinnati, OH, USA, 2004.

[9] A. Prüss-Ưstün, E. Rapiti, and Y. J. Hutin, Sharps Injuries: Global Burden of Disease from Sharps Injuries to Health-Care Workers, World Health Organization, Geneva, Switzerland, 2003.

[10] S. Musa, C. Peek-Asa, T. Young, and N. Jovanovic, "Needle stick injuries, sharp injuries and other occupational exposures to blood and body fluids among health care workers in a general hospital in Sarajevo, Bosnia and Herzegovina," International Journal of Occupational Safety and Health, vol. 4, no. 1, pp. 31-37, 2014.

[11] O. Amoran and O. Onwube, "Infection control and practice of standard precautions among healthcare workers in northern Nigeria," Journal of Global Infectious Diseases, vol. 5, no. 4, p. 156, 2013.

[12] N. Rajkumari, B. T. Thanbuana, N. V. John, J. Gunjiyal, P. Mathur, and M. C. Misra, "A prospective look at the burden of sharps injuries and splashes among trauma health care workers in developing countries: true picture or tip of iceberg," Injury, vol. 45, no. 9, pp. 1470-1478, 2014.

[13] L. Marković-Denić, M. Branković, N. Maksimović et al., "Occupational exposures to blood and body fluids among health care workers at university hospitals," Srpski arhiv za celokupno lekarstvo, vol. 141, no. 11-12, pp. 789-793, 2013.

[14] World Health Organization, The World Health Report 2002: Reducing Risks, Promoting Healthy Life, World Health Organization, Geneva, Switzerland, 2002.

[15] S. Mossburg, A. Agore, M. Nkimbeng, and Y. CommodoreMensah, "Occupational hazards among healthcare workers in Africa: a systematic review," Annals of Global Health, vol. 85, no. 1, 2019.

[16] W. D. Atlaw, Pattern of Occupational Exposure to Patients' Body Fluids among Health Care Workers in Tikuranbesa 
University Hospital, University of South Africa Addis Ababa, Addis Ababa, Ethiopia, 2013.

[17] Y. B. Belachew, T. B. Lema, G. N. Germossa, and Y. M. Adinew, "Blood/Body Fluid exposure and needle stick/ sharp injury among nurses Working in Public hospitals; southwest Ethiopia," Frontiers in Public Health, vol. 5, p. 299, 2017.

[18] H. Motaarefi, H. Mahmoudi, E. Mohammadi, and A. Hasanpour-Dehkordi, "Factors associated with needlestick injuries in health care occupations: a systematic review," Journal of Clinical and Diagnostic Research: JCDR, vol. 10, no. 8, pp. IE01-IE04, 2016.

[19] A. Nmadu, K. Sabitu, and I. Joshua, "Occupational exposure to blood and body fluids among primary health-care workers in Kaduna State, Nigeria," Journal of Medicine in the Tropics, vol. 18 , no. 2, p. 79, 2016

[20] A. A. Reda, S. Fisseha, B. Mengistie, and J.-M. Vandeweerd, "Standard precautions: occupational exposure and behavior of health care workers in Ethiopia," PLoS One, vol. 5, no. 12, Article ID e14420, 2010.

[21] H. Naderi, F. Sheybani, A. Bojdi, I. Mostafavi, and N. Khosravi, "Occupational exposure to blood and other body fluids among health care workers at a university hospital in Iran," Workplace Health \& Safety, vol. 60, no. 10, pp. 419-422, 2012.

[22] B. S. Gebremariyam, "Determinants of occupational exposure to blood and body fluids, healthcare workers' risk perceptions and standard precautionary practices: a hospital-based study in Addis Ababa, Ethiopia," Ethiopian Journal of Health Development, vol. 33, no. $1,2019$.

[23] World Health Organization, Responding To Intimate Partner Violence and Sexual Violence against Women: WHO Clinical and Policy Guidelines, World Health Organization, Geneva, Switzerland, 2013.

[24] CDC, "Recommendations for prevention of HIV trans-mission in health-care settings," MMWR. Morbidity and Mortality Weekly Report, vol. 36, no. 2, pp. 1S-19S, 1987.

[25] A. Gebresilassie, A. Kumei, and D. Yemane, "Standard precautions practice among health care workers in public health facilities of Mekelle special zone, Northern Ethiopia," Journal of Community Medicine \& Health Education, vol. 4, no. 3, p. 286, 2014.

[26] Service UPH, "Updated US Public Health Service Guidelines for the management of occupational exposures to HBV, HCV, and HIV and recommendations for postexposure prophylaxis. MMWR. Recommendations and reports: morbidity and mortality weekly report," Recommendations and Reports, vol. 50, no. RR-11, p. 1, 2001.

[27] B. Sahiledengle, A. Gebresilassie, T. Getahun, and D. Hiko, "Infection prevention practices and associated factors among healthcare workers in governmental healthcare facilities in Addis Ababa," Ethiopian Journal of Health Sciences, vol. 28, no. 2, pp. 177-186, 2018.

[28] J. Gammon, H. Morgan-Samuel, and D. Gould, "A review of the evidence for suboptimal compliance of healthcare practitioners to standard/universal infection control precautions," Journal of Clinical Nursing, vol. 17, no. 2, pp. 157-167, 2008.

[29] World Health Organization, WHO Guideline on the Use of Safety-Engineered Syringes for Intramuscular, Intradermal and Subcutaneous Injections in Health-Care Settings, World Health Organization, Geneva, Switzerland, 2015.

[30] M. Askarian, M. Yadollahi, F. Kuochak, M. Danaei, V. Vakili, and M. Momeni, "Precautions for health care workers to avoid hepatitis B and C virus infection," The International
Journal of Occupational and Environmental Medicine (The IJOEM), vol. 2, no. 4, pp. 191-198, 2011.

[31] Z. Fereidouni, M. Kameli Morandini, A. Dehghan, N. Jamshidi, and M. Najafi Kalyani, "The prevalence of needlestick injuries and exposure to blood and body fluids among Iranian healthcare workers: a systematic review," International Journal of Medical Reviews, vol. 5, no. 1, pp. 35-40, 2018.

[32] E. Amerga and T. Mekonnen, "Occupational exposure to blood and body fluids among health care workers in arada sub-city health centers of Addis Ababa, Ethiopia," Occupational Medicine \& Health Affairs, vol. 6, no. 4, p. 2, 2018.

[33] C. E. Cooke and J. M. Stephens, "Clinical, economic, and humanistic burden of needlestick injuries in healthcare workers," Medical Devices: Evidence and Research, vol. Volume 10, pp. 225-235, 2017.

[34] World Health Organization, Health workers: Health worker occupational health, https://www.who.int/occupational_ health/topics/hcworkers/en/.

[35] World Health Organization, Working Together for Health: The World Health Report 2006: Policy Briefs, World Health Organization, Geneva, Switzerland, 2006.

[36] G. Russo, L. Xu, M. McIsaac et al., "Health workers' strikes in low-income countries: the available evidence," Bulletin of the World Health Organization, vol. 97, no. 7, pp. 460-467H, 2019.

[37] J. W. Sohn, B. G. Kim, S. H. Kim, and C. Han, "Mental health of healthcare workers who experience needlestick and sharps injuries," Journal of Occupational Health, vol. 48, no. 6, pp. 474-479, 2006.

[38] A. Mannocci, G. De Carli, V. Di Bari et al., "How much do needlestick injuries cost? A systematic review of the economic evaluations of needlestick and sharps injuries among healthcare personnel," Infection Control \& Hospital Epidemiology, vol. 37, no. 6, pp. 635-646, 2016.

[39] J. Gold, M. Tomkins, P. Melling, and N. Bates, Guidance Note on Health Care Worker Safety from HIV and Other Blood Borne Infections, World Bank, Washington, DC, USA, 2004.

[40] Z. Y. Nigussie, T. E. Tafere, and G. T. Kassa, "Managements of exposure to blood and body fluids among healthcare workers and medical students in university of Gondar hospital, Northwest of Ethiopia," Global Journal of Medical Research, vol. 13, 2013.

[41] C. C. Mbah, "Reporting of accidental occupational exposures to blood and body fluids by doctors and nurses in the public primary health care setting of sub district F of Johannesburg Metropolitan district," A Research Report, Semantic Scholar, Allen Institute for AI, Seattle, WA, USA, 2014.

[42] S. Tadesse and D. Israel, "Occupational injuries among building construction workers in Addis Ababa, Ethiopia," Journal of Occupational Medicine and Toxicology, vol. 11, no. 1, p. 16, 2016.

[43] P. L. Chalya, J. Seni, M. F. Mushi et al., "Needle-stick injuries and splash exposures among health-care workers at a tertiary care hospital in north-western Tanzania," Tanzania Journal of Health Research, vol. 17, no. 2, 2015.

[44] I. Sabbah, H. Sabbah, S. Sabbah, H. Akoum, and N. Droubi, "Occupational exposures to blood and body fluids (BBF): assessment of knowledge, attitude and practice among health care workers in general hospitals in Lebanon," Health, vol. 5, no. 1, pp. 70-78, 2013.

[45] C. H. Ngwa, E. A. Ngoh, and S. N. Cumber, "Assessment of the knowledge, attitude and practice of health care workers in Fako Division on post exposure prophylaxis to blood borne 
viruses: a hospital based cross-sectional study," The Pan African Medical Journal, vol. 31, 2018.

[46] S. Shokuhi, L. Gachkar, I. Alavi-Darazam, P. Yuhanaee, and M. Sajadi, "Occupational exposure to blood and body fluids among health care workers in teaching hospitals in Tehran, Iran," Iranian Red Crescent Medical Journal, vol. 14, no. 7, pp. 402-407, 2012.

[47] M. Everline, N. Zipporah, W. Peter, and O. Jared, "Prevalence and factors associated with percutaneous injuries and splash exposures among health-care workers in a provincial hospital, Kenya," The Pan African Medical Journal, vol. 14, no. 10, 2013.

[48] M. Chakravarthy, S. Singh, A. Arora, S. Sengupta, and N. Munshi, "The epinet data of four indian hospitals on incidence of exposure of healthcare workers to blood and body fluid: a multicentric prospective analysis," Indian Journal of Medical Sciences, vol. 64, no. 12, p. 540, 2010.

[49] T. Yoshikawa, K. Wada, J. J. Lee et al., "Incidence rate of needlestick and sharps injuries in 67 Japanese hospitals: a national surveillance study," PLoS One, vol. 8, no. 10, Article ID e77524, 2013.

[50] C. Voide, K. E. Darling, A. Kenfak-Foguena, V. Erard, M. Cavassini, and C. Lazor-Blanchet, "Underreporting of needlestick and sharps injuries among healthcare workers in a Swiss University Hospital," Swiss Medical Weekly, vol. 142, pp. 1-7, 2012.

[51] L. K. Lee and I. N. Hassim, "Implication of the prevalence of needlestick injuries in a general hospital in Malaysia and its risk in clinical practice," Environmental Health and Preventive Medicine, vol. 10, no. 1, pp. 33-41, 2005.

[52] C. S. Kessler, M. McGuinn, A. Spec, J. Christensen, R. Baragi, and R. C. Hershow, "Underreporting of blood and body fluid exposures among health care students and trainees in the acute care setting: a 2007 survey," American Journal of Infection Control, vol. 39, no. 2, pp. 129-134, 2011.

[53] T. G. Haile, E. H. Engeda, and A. A. Abdo, "Compliance with standard precautions and associated factors among healthcare workers in Gondar University Comprehensive Specialized Hospital, Northwest Ethiopia," Journal of Environmental and Public Health, vol. 2017, Article ID 2050635, 8 pages, 2017.

[54] Y. L. Xu, J. Y. Zhu, C. F. Huang, X. Hu, and Y. H. Xiong, "Occupational exposure to blood and body fluids among dental personnel in a Chinese dental hospital," The Chinese Journal of Dental Research, vol. 16, no. 2, pp. 119-125, 2013.

[55] N. T. Sharew, G. B. Mulu, T. D. Habtewold, and K. D. Gizachew, "Occupational exposure to sharps injury among healthcare providers in Ethiopia regional hospitals," Annals of Occupational and Environmental Medicine, vol. 29, no. 1, p. 7, 2017.

[56] R. M. Laisser and J. F. Ng'home, "Reported incidences and factors associated with percutaneous injuries and splash exposures among healthcare workers in Kahama District, Tanzania," Tanzania Journal of Health Research, vol. 19, no. 1, 2017.

[57] V. G. Duffy, "Effects of training and experience on perception of hazard and risk," Ergonomics, vol. 46, no. 1-3, pp. 114-125, 2003.

[58] A. Lette, A. Ambelu, T. Getahun, and S. Mekonen, “A survey of work-related injuries among building construction workers in southwestern Ethiopia," International Journal of Industrial Ergonomics, vol. 68, pp. 57-64, 2018.

[59] J. M. Corkery, F. Schifano, A. Oyefeso et al., "Bundle of fun' or 'bunch of problems'? Case series of khat-related deaths in the UK," Drugs: Education, Prevention and Policy, vol. 18, no. 6, pp. 408-425, 2011. 